\title{
Incidence of myocardial infarction in women. A cohort study of risk factors and modifiers of effect
}

\author{
G Engström, P Tydén, G Berglund, O Hansen, B Hedblad, L Janzon
}

\begin{abstract}
Study objective-To assess whether the increased incidence of myocardial infarction and death associated with smoking, hypertension, hyperlipidaemia and diabetes varies significantly between groups defined in terms of occupation, education and marital status.

Setting-Malmö, Sweden.

Participants-9351 women, aged 28-55, with a mean follow up of 10.7 years.

Main results-Smoking, hypertension ( $\geqslant 160 / 95 \mathrm{~mm} \mathrm{Hg}$ or treatment), hyperlipidaemia (cholesterol $\geqslant 6.5 \mathrm{mmol} / 1$ or triglycerides $\geqslant 2.3 \mathrm{mmol} / \mathrm{l})$, diabetes, low occupation and education levels were significantly more common among women who experienced a fatal or nonfatal myocardial infarction during the follow up $(n=104)$ than in other women $(\mathbf{n}=9247)$. Exposure to smoking, hypertension and hyperlipidaemia showed substantial differences between groups defined in terms of education, occupation and marital status. The association between low occupation and myocardial infarction remained statistically significant after adjustments for several potential confounders $(R R=2.6,95 \% C I \quad 1.1,6.0)$. Single women had similarly higher adjusted mortality rates than married women $(R R=1.4,95 \% C I 1.1,1.8)$. When other major risk factors were taken into account, the relative risk for mortality and myocardial infarction associated with smoking was $2.6(95 \% \mathrm{CI} 2.0,3.4)$ and 7.8 (95\%CI 4.4, 13.9), respectively.

Conclusion-In this urban female population, short education and low occupation level were both associated with an increased prevalence of smoking, hypertension, hyperlipidaemia and diabetes. Low occupation level increases the rate of cardiac events caused by exposure to these four risk factors.
\end{abstract}

(F Epidemiol Community Health 2000;54:104-107)

In a statement for health care professionals from the American Heart Association in 1997 it was concluded that the major risk factors for coronary heart disease (CHD) in women are smoking, hypertension, hyperlipidaemia, diabetes, obesity, sedentary life style and poor nutrition. ${ }^{1}$

Incidence of disease has by others been found to vary between groups defined in terms of education, occupation and civil status. ${ }^{2-9}$ Whether in fact these markers may modify individual susceptibility or whether they rather should be considered factors modifying probability of exposure to the risk factors listed by the AHA remains controversial.

The aim of this cohort study of women from the city of Malmö in Sweden has been to assess whether the increased incidence of myocardial infarction and death associated with smoking, hypertension, hyperlipidaemia and diabetes varies significantly between groups defined in terms of occupation, education and marital status.

\section{Methods}

SUBJECTS

The study cohort consists of 9351 women, 28-55 years of age, who between May 1977 and February 1991 attended the health examination programme at the Department of Preventive Medicine in Malmö. ${ }^{10}$ A total of 9351 women corresponds to an attendance rate of $72 \%$.

Information on smoking habits was available for 9300 women, on blood pressure for 9297, on blood glucose for 9226, on serum lipid concentrations for 9314 women, civil status for 9255 women, on education for 8940 and on occupation for 9301 women. All cases were followed up from the baseline examination until the first cardiac event, death or 31 December 1994. Mean (SD) follow up time was 10.7 (4.3) years (range 0.3-17.9 years).

\section{Mortality and cardiac events}

Acute myocardial infarctions (ICD-9 code 410) and deaths attributable to ischaemic heart disease (ICD-9 code 410-414) were counted as cardiac events. ${ }^{11}$ New cases of nonfatal myocardial infarction were retrieved from the Malmö Myocardial Infarction Register. ${ }^{12}{ }^{13}$ This register is built on information from the patient administrative register at the Malmö University Hospital, which is the only hospital in Malmö that cares for and treats patients with myocardial infarction. Information on deaths from all causes and deaths attributable to ischaemic heart disease was retrieved by data linkage with the Swedish Causes of Deaths register. One hundred and four women had a cardiac event during the follow up period. Seven of those had a history of myocardial infarction before the baseline examination.

\section{SCREENING EXAMINATION}

The screening examination took place in the morning with subjects in smoke free and fasting condition. A computerised questionnaire was used for assessments of smoking habits, physical activity, diabetes mellitus, self reported stress and working conditions. ${ }^{10}$ 
Table 1 Cardiovascular risk factors in relation to education, occupation and marital status in 9351 women aged 28-55

\begin{tabular}{|c|c|c|c|c|c|c|c|}
\hline & \multicolumn{3}{|l|}{ Education } & \multicolumn{2}{|l|}{ Occupation } & \multicolumn{2}{|c|}{ Marital status } \\
\hline & $\begin{array}{l}\text { Primary } \\
\text { school }\end{array}$ & High school & $\begin{array}{l}\text { College or } \\
\text { university }\end{array}$ & Low level & High level & Married & $\begin{array}{l}\text { Single/widow/ } \\
\text { divorced }\end{array}$ \\
\hline \multicolumn{8}{|l|}{ Smoking } \\
\hline Never n (\%) & $2338(45.4)$ & $1026(44.0)$ & $629(44.6)$ & $3379(44)$ & $747(45)$ & $3181(48)$ & $920(35)$ \\
\hline Ex-smokers n (\%) & $860(16.7)$ & $425(18.2)$ & $400(28.4)$ & 1339 (18) & $418(25)$ & $1265(19)$ & $485(19)$ \\
\hline Current smokers n (\%) & $1948(37.9)$ & $883(37.8)$ & $380(27.0)$ & $2879(38)$ & $491(30)$ & $2160(33)$ & $1197(46)$ \\
\hline \multicolumn{8}{|l|}{ Age adjusted OR $(95 \% \mathrm{CI})$} \\
\hline Current smoker & 1.00 & $0.92(0.83,1.02)$ & $0.52(0.46,0.60)$ & 1.00 & $0.65(0.58,0.74)$ & 1.00 & $1.71(1.56,1.88)$ \\
\hline Hypertension $\mathrm{n}(\%)$ & $922(17.9)$ & $294(12.6)$ & $143(10.2)$ & $1233(16)$ & $189(11)$ & $1031(16)$ & $383(15)$ \\
\hline Age adjusted OR ( $95 \% \mathrm{CI})$ & 1.00 & $0.74(0.64,0.85)$ & $0.62(0.51,0.74)$ & 1.00 & $0.71(0.60,0.84)$ & 1.00 & $0.99(0.87,1.12)$ \\
\hline Hyperlipidaemia n (\%) & $1416(27.5)$ & $517(22.1)$ & $230(16.3)$ & $1939(25)$ & $316(19)$ & $1578(24)$ & $660(25)$ \\
\hline Age adjusted OR $(95 \% \mathrm{CI})$ & 1.00 & $0.87(0.77,0.97)$ & $0.64(0.54,0.75)$ & 1.00 & $0.74(0.64,0.85)$ & 1.00 & $1.17(1.05,1.31)$ \\
\hline Diabetes n (\%) & $133(2.6)$ & $34(1.5)$ & $16(1.1)$ & $164(2.2)$ & $24(1.5)$ & $134(2.0)$ & $53(2.1)$ \\
\hline Age adjusted OR $(95 \% \mathrm{CI})$ & 1.00 & $0.63(0.43,0.93)$ & $0.53(0.31,0.89)$ & 1.00 & $0.72(0.47,1.11)$ & 1.00 & $1.07(0.77,1.47)$ \\
\hline
\end{tabular}

Smoking

Probands who were smoking daily were categorised as "current smokers", probands who previously had been smoking for at least six months but who had stopped smoking were denoted "ex-smokers". Women who had not smoked for at least six months were categorised as "never smokers".

Stress and working conditions

Probands who reported that they disliked their work or who worked much overtime were considered to have unsatisfactory working conditions. Probands who confirmed periods of stress during the past five years, stress at work, difficulties to relax after a normal working day or difficulties to fall asleep were considered to have self reported stress.

Blood pressure, blood glucose, serum lipids

Blood pressure ( $\mathrm{mm} \mathrm{Hg}$ ) was measured twice in the right arm in supine position after a 10 minute rest. The average of two measurements was used. A sphygmomanometer and a rubber cuff of appropriate size were used. Hypertension was defined as systolic blood pressure $\geqslant 160 \mathrm{~mm} \mathrm{Hg}$, diastolic blood pressure $\geqslant 95$ $\mathrm{mm} \mathrm{Hg}$ or medical treatment of hypertension. ${ }^{14}$

Serum cholesterol and triglyceride concentrations after an overnight fast were analysed with standard methods at the laboratory of the hospital. Hyperlipidaemia was defined as total cholesterol concentrations $\geqslant 6.5 \mathrm{mmol} / 1$ (251 $\mathrm{mg} / \mathrm{dl})$ or triglyceride levels $\geqslant 2.3 \mathrm{mmol} / \mathrm{l}$ (204 $\mathrm{mg} / \mathrm{dl}) .{ }^{15}$

Body mass index (BMI) was calculated as weight $/$ height $^{2}\left(\mathrm{~kg} / \mathrm{m}^{2}\right)$.

Blood glucose was analysed with a hexokinase method. ${ }^{16}$ Women with a fasting blood sugar $\geqslant 6.7 \mathrm{mmol} / 1$ or who reported treatment of diabetes were considered to have diabetes.

Education, occupation, marital status

Information on marital status, education and occupation was retrieved by data linkage with national census registers. High and medium level non-manual workers and self employed women (SEI groups 46-79) were categorised as "high" occupational groups. Low level nonmanual workers, manual workers (SEI groups 11-36 and 91-99) and unspecified occupational groups (early retired women, housewives, students, unemployed) were categorised as "low" occupational groups. ${ }^{17}$

\section{STATISTICS}

Logistic regression analyses were used when adjusting the odds ratios for smoking, hypertension and hyperlipidaemia in groups with different education, occupation and marital status for the influence of age. Univariate comparisons of women with and without cardiac events during the follow up were similarly carried out by means of logistic regressions. Cox's proportional hazards model ${ }^{18}$ was used to estimate the relative risk for cardiac events and mortality in different risk factor categories after adjustments for potential confounders. In addition to occupation, education and marital status, variables with significant differences between cases and controls (age, smoking habits, hypertension, hyperlipidaemia, diabetes, and history of myocardial infarction) were included in the analysis. The fit of the proportional hazards model was examined by plotting the hazards functions in different categories of

Table 2 Mortality and cardiac event rates in women in relation to risk factor category

\begin{tabular}{|c|c|c|c|c|c|c|c|}
\hline & $\begin{array}{l}\text { Number } \\
n(\%)\end{array}$ & $\begin{array}{l}\text { Deaths } \\
n(\%)\end{array}$ & $\begin{array}{l}\text { Follow up } \\
(P Y)\end{array}$ & $\begin{array}{l}\text { Deaths/1000 PY } \\
(95 \% \mathrm{CI})\end{array}$ & $\begin{array}{l}\text { Cardiac } \\
\text { events } \\
n(\%)\end{array}$ & $\begin{array}{l}\text { Follow up } \\
(P Y)\end{array}$ & $\begin{array}{l}\text { Events/1000 PY } \\
(95 \% \text { CI) }\end{array}$ \\
\hline \multicolumn{8}{|l|}{ Occupation } \\
\hline High & 1660 & $38(2.3)$ & 17854 & $2.13(1.51,2.92)$ & $6(0.4)$ & 17843 & $0.34(0.12,0.73)$ \\
\hline Low & 7643 & $246(3.2)$ & 81834 & $3.01(2.64,3.41)$ & $98(1.3)$ & 81558 & $1.20(0.97,1.46)$ \\
\hline \multicolumn{8}{|l|}{ Marital status } \\
\hline Married & 6639 & $178(2.7)$ & 71249 & $2.50(2.14,2.89)$ & $71(1.1)$ & 71060 & $1.00(0.78,1.26)$ \\
\hline Single & 2616 & $105(4.0)$ & 28086 & $3.74(3.06,4.53)$ & $33(1.3)$ & 27988 & $1.18(0.81,1.66)$ \\
\hline \multicolumn{8}{|l|}{ Education } \\
\hline Primary school & 5177 & $110(2.1)$ & 55270 & $1.99(1.64,2.40)$ & $64(1.2)$ & 55057 & $1.16(0.90,1.48)$ \\
\hline High school & 2351 & $30(1.3)$ & 25268 & $1.19(0.80,1.69)$ & $21(0.9)$ & 25214 & $0.83(0.52,1.27)$ \\
\hline College/university & 1412 & $19(1.3)$ & 15435 & $1.23(0.74,1.92)$ & $3(0.2)$ & 15424 & $0.19(0.04,0.57)$ \\
\hline All & 9351 & $286(3.1)$ & 100167 & $2.86(2.53,3.21)$ & $104(1.1)$ & 99881 & $1.04(0.85,1.26)$ \\
\hline
\end{tabular}

PY=person years. 
Table 3 Baseline characteristics in women who had and had not a cardiac event during an average of 10.7 years follow up. Mean (SD) and unadjusted odds ratios (OR). For age and BMI expressed as relative risks associated with 1 unit increase

\begin{tabular}{|c|c|c|c|}
\hline Variable & $\begin{array}{l}\text { No cardiac event } \\
(n=9247)\end{array}$ & $\begin{array}{l}\text { Cardiac event } \\
(n=104)\end{array}$ & OR $(95 \% C I)$ \\
\hline Age (years, mean (SD), range) & $48.5(7.4)(28-55)$ & $51.0(5.6)(29-55)$ & $1.06(1.02,1.10)$ \\
\hline \multicolumn{4}{|l|}{ Smoking habits } \\
\hline Never smoked, n (\%) & $4537(45)$ & $14(14)$ & reference \\
\hline Former smoker, n (\%) & $1747(19)$ & $15(14)$ & $2.54(1.2,5.3)$ \\
\hline Current smoker, n (\%) & $3312(36)$ & $75(72)$ & $6.69(3.8,11.6)$ \\
\hline \multicolumn{4}{|c|}{ Mostly sedentary during leisure time ${ }^{\star}$} \\
\hline No & $6432(81)$ & $78(79)$ & reference \\
\hline Yes n $(\%)$ & $1505(19)$ & $21(21)$ & $1.15(0.71,1.9)$ \\
\hline Body mass index $\left(\mathrm{kg} / \mathrm{m}^{2}\right)$ & $24.2(4.1)$ & $24.6(3.7)$ & $1.026(0.98,1.07)$ \\
\hline \multicolumn{4}{|l|}{ Hypertension $\mathrm{n}(\%)$} \\
\hline No & $7794(85)$ & $72(69)$ & reference \\
\hline Yes & $1399(15)$ & $32(31)$ & $2.48(1.6,3.8)$ \\
\hline \multicolumn{4}{|l|}{ Diabetes mellitus, n (\%) } \\
\hline No & $8943(98)$ & $91(88)$ & reference \\
\hline Yes & $179(2)$ & $13(13)$ & $7.1(3.9,13.0)$ \\
\hline \multicolumn{4}{|l|}{ Hyperlipidaemia n (\%) } \\
\hline No & $6987(76)$ & $61(59)$ & reference \\
\hline Yes & $2224(24)$ & $42(41)$ & $2.16(1.46,3.21)$ \\
\hline \multicolumn{4}{|l|}{ Education $\dagger$} \\
\hline Pimary school, n (\%) & $5113(58)$ & $64(73)$ & reference \\
\hline High school, n (\%) & $2330(26)$ & $21(24)$ & $0.72(0.44,1.18)$ \\
\hline College/university, n (\%) & $1409(16)$ & $3(2.4)$ & $0.17(0.05,0.54)$ \\
\hline \multicolumn{4}{|l|}{ Occupation } \\
\hline High level, n (\%) & $1654(18)$ & $6(6)$ & reference \\
\hline Low level, n (\%) & $7543(82)$ & $98(94)$ & $3.58(1.57,8.17)$ \\
\hline \multicolumn{4}{|l|}{ Marital status n (\%) } \\
\hline Married & $6568(72)$ & $71(68)$ & reference \\
\hline Single & $2583(28)$ & $33(31)$ & $1.18(0.78,1.79)$ \\
\hline \multicolumn{4}{|l|}{ Working conditions ${ }^{\star}$} \\
\hline Satisfactory & $7460(94)$ & $90(91)$ & reference \\
\hline Non-satisfactory & $476(6)$ & $9(9)$ & $1.57(0.78,3.13)$ \\
\hline \multicolumn{4}{|l|}{ Self reported stress } \\
\hline No & $4276(52)$ & $43(43)$ & reference \\
\hline Yes & $3966(48)$ & $58(57)$ & $1.45(0.98,2.16)$ \\
\hline \multicolumn{4}{|l|}{ Previous myocardial infarction } \\
\hline No & $9208(99.6)$ & $97(93.3)$ & reference \\
\hline Yes & $39(0.4)$ & $7(6.7)$ & $17.0(7.4,39.0)$ \\
\hline
\end{tabular}

Because of missing information analysis is based on $\left(^{\star}\right) 99$ cases and 7936 controls and on $(\dagger) 88$ cases and 8852 controls, respectively.

risk factors over time. The results indicated that the application of the model was appropriate.

\section{Results}

EXPOSURE IN RELATION TO EDUCATION, OCCUPATION, MARITAL STATUS AND AGE

The prevalence of all risk factors was higher in women with low education and occupation levels (table 1). Smoking and hyperlipidaemia was more prevalent in single than in married women (table 1).

In the youngest age group (28-40 years, $\mathrm{n}=1577) 47 \%$ were smokers, $6.9 \%$ had hypertension, $8.8 \%$ had hyperlipidaemia and $0.2 \%$ had diabetes. In the oldest age group (51-55 years, $n=4281$ ), $32 \%$ were smokers, $20 \%$ had
KEY POINTS

- Exposure to cardiovascular risk factors varies substantially between groups of women defined in terms of education, occupation and marital status.

- This variation does not fully explain the higher rate of myocardial infarction in women with low occupation level or the higher mortality rate among single women.

- Smoking contributes more than hypertension, hyperlipidaemia and diabetes to the incidence of myocardial infarction in middle aged urban women.

hypertension, 35\% had hyperlipidaemia and $3.1 \%$ had diabetes.

MORTALITY AND CARDIAC EVENT RATES

Two hundred and eighty six (2.86/1000 person years) women died during the follow up period, 28 in this group died from ischaemic heart disease (ICD 410-414). One hundred and four (1.04/1000 person years) had a fatal or non-fatal cardiac event during the follow up period (table 2).

RISK FACTORS IN RELATION TO CARDIAC EVENTS Smoking habits, age, diabetes, hypertension, hyperlipidaemia, occupation and education were all significantly associated with cardiac events (table 3 ).

MULTIVARIATE ANALYSIS

Smoking, hypertension, and diabetes remained significantly associated with mortality and cardiac events after adjustments for possible confounders (table 4). The associations between marital status and mortality $(\mathrm{RR}=1.4,95 \% \mathrm{CI}$ $1.1,1.8)$ and between occupation level and cardiac events ( $\mathrm{RR}=2.6,95 \% \mathrm{CI} 1.1,6.0)$ remained similarly statistically significant when other risk factors were taken into account.

\section{Discussion}

A number of studies have shown that mortality and incidence of myocardial infarction varies between groups defined in terms of education, occupation and civil status. $.^{2-9} 19-21$ Although pattern of disease is strongly related to the prevalence of hypertension, smoking,

Table 4 Cox proportional hazards regression model. Adjusted relative risks (see footnotes) for mortality and cardiac events $(95 \% C I)$

\begin{tabular}{|c|c|c|c|c|}
\hline \multirow[b]{2}{*}{ Variable } & \multicolumn{2}{|l|}{ Mortality } & \multicolumn{2}{|l|}{ Cardiac events } \\
\hline & Model $1^{\star}$ & Model $2 f$ & Model $1^{\star}$ & Model $2 f$ \\
\hline Hypertension (yes $v$ no) & $1.6(1.2,2.1)$ & $1.7(1.3,2.3)$ & $2.0(1.3,3.1)$ & $2.4(1.6,3.6)$ \\
\hline Diabetes (yes $v$ no) & $3.6(2.3,5.6)$ & $2.9(1.8,4.6)$ & $6.4(3.6,11.6)$ & $4.4(2.4,8.2)$ \\
\hline Hyperlipidaemia (yes $v$ no) & $1.3(1.0,1.7)$ & $1.1(0.88,1.5)$ & $1.8(1.2,2.8)$ & $1.4(0.94,2.1)$ \\
\hline \multicolumn{5}{|l|}{ Smoking habits } \\
\hline Former $v$ never & $1.5(1.1,2.2)$ & $1.5(1.04,2.1)$ & $2.8(1.3,5.8)$ & $2.7(1.3,5.7)$ \\
\hline Current $v$ never & $2.5(1.9,3.2)$ & $2.6(2.0,3.4)$ & $7.5(4.2,13.2)$ & $7.8(4.4,13.9)$ \\
\hline Civil status (single $v$ married) & $1.6(1.3,2.1)$ & $1.4(1.1,1.8)$ & $1.3(0.86,2.0)$ & $1.05(0.69,1.6)$ \\
\hline Occupation (low $v$ high level) & $1.25(0.89,1.8)$ & $1.1(0.78,1.6)$ & $3.1(1.4,7.2)$ & $2.6(1.1,6.0)$ \\
\hline \multicolumn{5}{|l|}{ Education } \\
\hline High school $v$ primary school & $0.79(0.53,1.2)$ & $0.89(0.59,1.3)$ & $0.87(0.53,1.4)$ & $0.97(0.58,1.6)$ \\
\hline University $v$ primary school & $0.94(0.58,1.5)$ & $1.29(0.78,2.1)$ & $0.23(0.07,0.53)$ & $0.35(0.11,1.1)$ \\
\hline
\end{tabular}

^Adjusted for age. †Adjusted for age, hypertension, diabetes, hyperlipidaemia, history of myocardial infarction, and smoking habits. 
hyperlipidaemia and diabetes it seems that susceptibility associated with exposure to these risk factors may be modified by occupational and educational circumstances. The increased cardiac event rate associated with being single disappeared however in the multivariate analysis after adjustment for known major risk factors.

Differences with regard to use of tobacco between educational and occupational groups were mainly a matter of the proportion of ex-smokers as the percentage of never smokers in all groups was rather similar. This is in line with results from other studies. ${ }^{5223}$ To what extent differences in tobacco exposure may be related to knowledge about the potential health hazards respectively to use of tobacco as a coping strategy remains to be evaluated. According to results from cross sectional studies it seems that social support is associated with higher smoking cessation rate. ${ }^{24}$ The lower prevalence of smokers among married women is compatible with that view.

Exposure to hypertension, hyperlipidaemia and diabetes did similarly vary between occupational and educational groups. This is in accordance with several previous studies. ${ }^{3-59}$ As almost $28 \%$ of those invited did not attend the examination it is appropriate to question whether differences with regard to exposure to these major risk factors could have been confounded by selection bias-that is, by a lower participation rate among well educated and well to do subjects with hypertension, hyperlipidaemia or diabetes. As no attempt was made to approach non-responders this remains a possibility. Studies of non-participants in other cohort studies from the city do however not support this assumption. ${ }^{25}$

Another relevant issue is whether differences with regard to survival and incidence of cardiac events could have been confounded by biased retrieval and validation of cases. No proband was lost to follow up. Cause of death was based on necropsy in $52 \%$. As to the incidence of myocardial infarction there is in the city of Malmö one single hospital for referral of cases. Furthermore, morbidity and mortality in ischemic heart disease has for about 25 years continuously been monitored by the Malmö myocardial infarction register. ${ }^{12} 13$

Qualified education and occupation were both associated with a reduced incidence of cardiac events. No corresponding effect was observed with regard to mortality. As only 28 of the in all 286 deaths were caused by ischemic heart disease it may simply reflect lack of power. The increased mortality among women who were single remained statistically significant after adjustment for smoking and other potential confounders. Our results do not indicate that this association is attributable to an increased susceptibility for ischemic heart disease.

Smoking was in terms of relative risk and prevalence by far the most significant risk factor for myocardial infarction and death. Expressed in terms of attributable risk $^{26}$ it can be estimated that smoking explains $71 \%$ of events of myocardial infarction and $37 \%$ of the deaths in this cohort.

Low level of education and low occupation level were both associated with an increased prevalence of smoking, hypertension, hyperlipidaemia and diabetes. Low occupation level increases the rate of cardiac events caused by exposure to these four risk factors.

Conflicts of interest: none.

Funding: the study was supported by grants from the Vardal foundation and the Swedish Council for Social Research.

1 Mosca L, Manson JE, Sutherland SE, et al. Cardiovascular disease in women. A statement for healthcare professionals from the American Heart Association. Circulation 1997;96:2468-82

2 Pekkanen J, Tuomiletho J, Uutela A, et al. Social class, health behaviour, and mortality among men and women in eastern Finland. BMF 1995;311:589-93.

3 Pekkanen J, Uutela A, Valkonen T, et al. Coronary risk factor levels: Differences between educational groups in 1972-87 in eastern Finland. F Epidemiol Community Health 1995;49:144-9.

4 Kaplan GA, Keil JE. Socioeconomic factors and cardiovascular disease: A review of the literature. Circulation 1993;88:1973-98.

5 Matthews KA, Kelsey SF, Meilahn EN, et al. Educational attainment and behavioral and biologic risk factors for coronary heart disease in middle-aged women. Am 7 Epidemiol 1989;129:1132-44.

6 Brezinka V, Kittel F. Psychosocial factors of coronary heart disease in women: a review. Soc Sci Med 1996;42:1351-65.

7 Adler NE, Boyce WT, Chesney MA, et al. Socioeconomic inequalities in health. No easy solution. $\mathscr{f} A M A$ 1993;269: 3140-5.

8 Rosengren A, Wedel H, Wilhelmsen L. Marital status and mortality in middle-aged Swedish men. Am f Epidemiol 1989;129:54-64.

9 Rosengren A, Wedel H, Wilhelmsen L. Coronary heart disease and mortality in middle-aged Swedish men from different occu

10 Berglund G, Eriksson KF, Israelsson B, et al. Cardiovascular risk groups and mortality in an urban Swedish male population: the Malmö Preventive Project. F Intern Med 1996;239:489-97.

11 International Classification of Diseases, Ninth revision (ICD-9). Geneva: World Health Organization, 1977.

12 Hansen O, Johansson BW. Epidemiological aspects of coronary heart disease in Malmö, Sweden 1935-1988. Am f Epidemiol 1991;133:721-33.

13 Tydén P, Hansen O, Janzon L. Intra-urban variations in incidence and mortality in myocardial infarction. A study from the myocardial infarction register in the city of Malmö, Sweden. Eur Heart f 1998;19:1795-801.

14 WHO. 1986 guidelines for the treatment of mild hypertension: memorandum from a WHO/IHS meeting. $\mathcal{F}$

Hypertens 1986;4:383-6.
15 Treatment of hyperlipidemia. Recommendations. [In Swedish]. Information from the Medical Products Agency, Sweden. 1995;6:178-87.

16 Carrol JJ, Smith N, Babson AL. A colorimetric serum glucose determination using hexokinase and glucose-6-
phosphate dehydrogenase. Biochem Med 1970;4:171-80.

17 Statistics Sweden. Swedish Socioeconomic Classification (SEI), Reports on Statistical Co-ordination. Stockholm: Statistics Sweden, 1982:244-8

18 Cox DR. Regression models and life tables. I R Stat Soc 1972;34:187-220.

19 Marmot MG, Rose G, Shipley M, et al. Employment grade and coronary heart disease in British civil servants. $\mathcal{F}$ Epidemiol Community Health 1978;32:244-9.

20 Buring JE, Evans DA, Fiore M, et al. Occupation and risk of death from coronary heart disease. $\mathcal{F} A M A$ 1987;258:791-

21 Tucker JS, Friedman HS, Wingard DL, et al. Marital history at mid-life as a predictor of longevity: alternative history at mid-life as a predictor of longevity: alternative explanations to the pro
Psychol 1996;15:94-101.

22 Tillgren P, Haglund BJ, Lundberg $M$, et al. The sociodemographic pattern of tobacco cessation in the 1980s: results from a panel study of living conditions surveys in Sweden. F Epidemiol Community Health 1996;50: 625-30.

23 Pierce JP, Fiore MC, Novotny TE, et al. Trends in cigarette smoking in the United States. Educational differences are increasing. FAMA 1989;261:56-60.

24 Hanson BS, Isacsson SO, Janzon L, et al. Social support and quitting smoking for good. Is there an association? Results from the population study "Men born in 1914", Malmö, Sweden. Addict Behav 1990;15:221-33.

25 Janzon L, Hanson BS, Isacsson SO, et al. Factors influencing participation in health surveys. F Epidemiol Community Health 1986;40:174-7.

26 Armitage P, Berry G. Statistical methods for rates and proportions. 2nd ed. Oxford: Blackwell, 1987. 